\title{
Detection of a Specific DNA Fragment by Free-Solution Capillary Electrophoresis Using a Fluorescent DNA Probe Measured by Semiconductor Laser-Induced Fluorometry
}

\author{
Takashi KANETA*, Tadashi OKAMOTo** and Totaro IMASAKA*† \\ *Department of Chemical Science and Technology, Faculty of Engineering, Kyushu University, \\ Hakozaki, Fukuoka 812, Japan \\ **R\&D Headquarters, Canon Research Center, Canon Inc., \\ Morinosato-Wakamiya, Atsugi, Kanagawa, 243-01, Japan
}

\begin{abstract}
Semiconductor laser-induced fluorescence detection of native (target) DNA has been accomplished by free-solution capillary electrophoresis (CE) using an oligonucleotide labeled with a cyanine dye as a DNA probe. A mixture of probe DNA and target DNA, which is complementary to probe DNA, is incubated to form hybrid DNA; the mixture is then injected into a capillary. Single-stranded probe DNA and double-stranded hybrid DNA were separated by free-solution CE. A 19mer oligonucleotide labeled with fluorescein isothiocyanate (FITC) was used as probe DNA in a preliminary study. The stability of double-stranded DNA during migration was evaluated by changing the temperature of the solution in the capillary, i.e. the applied voltage in CE. The dissociation of double-stranded DNA was appreciable at high applied voltages. Thus, suppressing the temperature in the capillary, i.e. optimization of the voltage, was required in order to prevent the dissociation of double-stranded DNA. Furthermore, a new labeling reagent, a cyanine derivative, was synthesized in order to be applied to semiconductor laser-induced fluorometry. The detection limit was $8 \times 10^{-9} \mathrm{M}$ for probe DNA.
\end{abstract}

Keywords Capillary electrophoresis, semiconductor laser-induced fluorometry, cyanine dye, DNA, hybridization

Capillary electrophoresis $(\mathrm{CE})^{1,2}$ combined with laserinduced fluorometry (LIF) is a powerful technique for trace analysis ${ }^{3}$, because of high separation efficiency, high sensitivity, short time for analysis, and small sample amount required $(\sim 1 \mathrm{nl})$. Thus, CE-LIF is especially suitable for the analysis of biological samples. Semiconductor LIF is more practical, since a semiconductor laser is compact and easy to operate. . $^{4-7}$ We have also reported on the ultratrace analysis of amino acids by CE-semiconductor LIF;8,9 detection limits of 0.8 -4.5 attomole have been achieved using this approach. ${ }^{10}$

Recently, several scientists have demonstrated DNA sequencing using capillary gel electrophoresis (CGE) combined with LIF. ${ }^{11-13}$ CGE will become an alternative technique to conventional slab-gel electrophoresis, since it offers advantages in terms of speed and quantitation. In LIF detection, an argon ion laser is frequently used as a light source to excite tagged dye molecules. Chen et al. have reported that a cyaninelabeled primer can be used for DNA sequencing in CGEsemiconductor LIF. ${ }^{14}$ This technique is very practical because of the inexpensiveness of the laser source and of the simplified analytical instrument.

\footnotetext{
$\dagger$ To whom correspondence should be addressed.
}

On the other hand, one of the most important purposes in DNA analysis is the detection of a specified sequence among DNA fragments. A Southern blot technique ${ }^{15}$, a common way to detect a specified sequence, is troublesome, since it contains several complicated steps: separation of the fragments by slab-gel electrophoresis, transfer of the DNA fragments from the gel to a filter, hybridization of target DNA with probe DNA, and the detection of probe DNA based on the radio activity and fluorescence. More recently, some researchers have reported on an on-line Southern Blotting technique performed by CGE. ${ }^{16-18}$ However, CGE is somewhat less practical in routine analysis, since a gel-filled capillary has some technological problems, such as a short lifetime and difficulties in reproduction and maintenance. Liquid hybridization with an FITClabeled probe DNA and subsequent analysis of the hybrid DNA by capillary DNA chromatography is carried out using a chemically-modified capillary column filled with a cationic surfactant solution at above a critical micellar concentration, as well as a hydrodynamic pressure or high electric potential to flow the solution; the sample is considered to be separated by partition between the coated layer on a capillary and the mobile phase. ${ }^{19}$ Recently, Carlsson et al. have reported on screening for 
genetic mutations by free-solution $\mathrm{CE}$ using peptide nucleic acid (PNA) as a probe. ${ }^{20}$ After hybridization of DNA and PNA, DNA-PNA complexes are separated from free DNAs. Since DNA-PNA hybrid complexes easily melt unless the sequence is a perfect match, mutant DNA-PNA complexes are not detected. Thus, mutant DNAs can be distinguished from wild-type DNAs. As demonstrated, free-solution CE (or micellar electrokinetic chromatography (MEKC)) containing no gel is more straightforward and is practical for the separation of specified DNA because of flexibilities in the operation of the system and controlling the conditions.

In free-solution CE, a DNA molecule has an electrophoretic mobility determined by the ratio of the electric charge to its friction coefficient. Thus, since the mobility is not necessarily dependent on the molecular size, their separation is sometimes difficult without using any additives, such as metal ions. ${ }^{21}$ This is the reason why DNA fragments are frequently separated using a gelfilled capillary. Recently, Mayer et al. have reported that DNA can theoretically be separated in free-solution CE by labeling the end of the DNA with a chemical so as to introduce additional friction and charge. ${ }^{22}$ It thus seems to be probable that the mobility of doublestranded(ds)-DNA becomes appreciably different from that of single-stranded(ss)-DNA by the incorporation of FITC into DNA.

The present paper reports on a method used to detect a specific DNA fragment by semiconductor LIF using an oligonucleotide labeled with a near-infrared fluorescent dye. After hybridization of the target DNA with probe DNA, ss-DNA (probe DNA) and ds-DNA (hybrid DNA) are separated by MEKC as well as free-solution $\mathrm{CE}$, and detected by semiconductor LIF. In a preliminary study, FITC-labeled DNA was used as probe DNA. The separation was accomplished under careful control of the applied voltage so as not to dissociate dsDNA due to the temperature rise. An oligonucleotide labeled with a cyanine derivative has been newly synthesized, and is being used as a probe to demonstrate the advantage of semiconductor LIF.

\section{Experimental}

\section{Apparatus}

The LIF detection system in CE was described in a previous paper. ${ }^{8}$ All of the separations were performed in untreated capillaries (GL Sciences Inc. Tokyo, Japan, $50 \mu \mathrm{m}$ i.d., $375 \mu \mathrm{m}$ o.d., $40 \mathrm{~cm}$ long) without suppressing the electroosmotic flow. Sample injection was carried out at the positive end of a capillary filled with a buffer solution by a siphon method. Platinum wires were immersed into both sides of the buffer solutions as electrodes in order to apply a high potential (typically $20 \mathrm{kV}$ ). A high voltage power supply (Model HCZE30PN0.25 (Matsusada Precision Devices, Shiga, Japan)) was used to apply a voltage. Fluorescence detection was carried out at a position $10 \mathrm{~cm}$ away from the negative end of the capillary, at which point a polyimide coating was burned off by a flame. An argon ion laser (Model GLG3200 (Nippon Electric Company, Tokyo, Japan)) and a semiconductor laser (Model MINI-780F100 (Opto-Science Inc., Tokyo, Japan)) were used as light sources. The fluorescence spectrum of the sample was measured using a Model FP-770 spectrofluorometer (JASCO, Tokyo, Japan). The absorption spectrum was measured using a Model UV 3100S spectrophotometer (Shimadzu, Kyoto, Japan). High-performance liquid chromatography (HPLC) was performed using a Model 625 equipped with a $600 \mathrm{E}$ system controller and a 991 photodiode array detector (Waters, Milford, MA). An HPLC column (Lichro CART, Superspher 100RP-18(e); $4 \mu \mathrm{m}, 125 \mathrm{~mm}$ long, $4 \mathrm{~mm}$ o.d.; from Merck (Darmstadt, GFR)) was used to purify oligonucleotides. During all of the electrophoretic separations, the room temperature was kept at $23^{\circ} \mathrm{C}$.

\section{Chemicals}

All of the reagents used were of analytical grade. Sodium dodecylsulfate (SDS), tris(hydroxymethyl)aminomethane (Tris), and sodium dihydrogenphosphate were obtained from Wako Pure Chemicals (Osaka, Japan). The starting compound of the cyanine dye (see Fig. 1) was supplied from Nippon Kanko-Shikiso Kenkyusho (Code number, NK-3759: Okayama, Japan), $N, N^{\prime}$ -

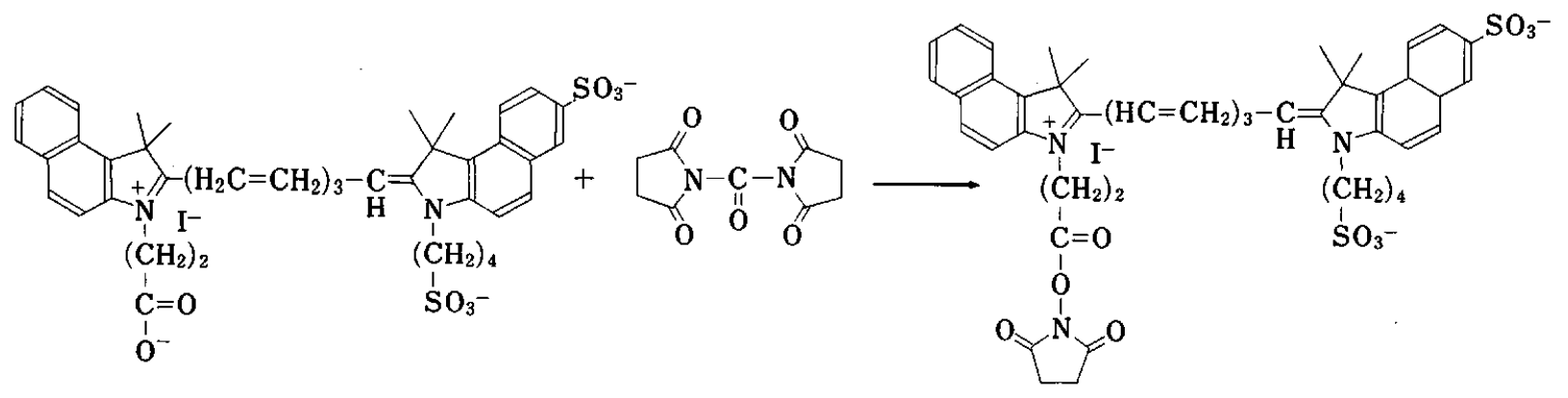

Fig. 1 Scheme for synthesis of cyanine labeling reagent. 
succinimidylcarbonate from Aldrich (Milwaukee, WI), fluorescein isothiocyanate (FITC) from Sigma Chemical Co. (St. Louis, MO), acetonitrile (HPLC grade) from Nacalai Tesque (Tokyo, Japan), and dimethylformamide (spectra grade) and pyridine (dehydrated) from Kanto Kagaku Co. (Tokyo, Japan). The migration buffer solution was prepared as follows: after $3 \mathrm{mmol}$ of SDS was dissolved in water, $0.5 \mathrm{ml}$ of $1 \mathrm{M}$ sodium dihydrogenphosphate and $0.25 \mathrm{ml}$ of $1 \mathrm{M}$ Tris were added in turn. Finally, this solution was filled up to $50 \mathrm{ml}$ with water. Thus, the concentration was $60 \mathrm{mM}$ for SDS, $10 \mathrm{mM}$ for sodium dihydrogenphosphate, and $5 \mathrm{mM}$ for Tris ( $\mathrm{pH} 7)$. Hybridization was performed in a buffer solution containing $60 \mathrm{mM}$ of sodium dihydrogenphosphate and $30 \mathrm{mM}$ of Tris.

\section{Synthesis of a cyanine labeling reagent}

The scheme for synthesis of a cyanine derivative for labeling DNA is shown in Fig. 1. After dissolving $170 \mathrm{mg}$ of cyanine dye in $5 \mathrm{ml}$ of dry dimethylformamide, dry pyridine was added to the solution. Upon adding $128 \mathrm{mg}$ of $N, N^{\prime}$-succinimidylcarbonate, the solution was stirred for $20 \mathrm{~h}$ at room temperature in the dark. After adding diethyl ether to the mixture solution, the precipitate was filtered and washed with diethyl ether, and then dried. It was then used as a labeling reagent without further purification.

\section{Synthesis of oligonucleotides}

All of the oligonucleotides were synthesized using Model 381A DNA synthesizer (Applied Biosystems, Foster City, CA). Probe DNA (oligonucleotides, 19mer; 5'-TTG-TAA-AAC-GAC-CGC-CAG-T) has a complementary sequence to target DNA (oligonucleotides, 19mer; 3'-AAC-ATT-TTG-CTG-GCG-GTC-A), which is contained in the sequence of M13mp18ssDNA. The start of probe DNA synthesis followed a standard protocol, and was combined with Hexanolamine Linker (MilliGen/Biosearch, Division of Millipore, Burlington, MA) at the $5^{\prime}$ end. The amino group in this linker was then incorporated with a fluorescent labeling reagent (FITC or cyanine dye).

\section{Synthesis of probe DNA}

An oligonucleotide, in which an amino group was introduced, was dissolved in a sodium phosphate buffer $(170 \mathrm{mM}, \mathrm{pH} 7)$; the labeling reagent was then added to this solution. The mixture was left standing for $24 \mathrm{~h}$ at $40^{\circ} \mathrm{C}$. After crude purification using a gel filtration column (NAP-50, Pharmacia, Tokyo, Japan), the product was further purified by conventional HPLC (mobile phase; $0.1 \mathrm{M}$ triethylammonium acetate buffer and $5-50 \%$ acetonitrile gradient).

\section{Hybridization}

The required amounts of the probe and target DNA solutions were mixed in a vassal, which was immersed for $10 \mathrm{~min}$ in a water bath kept at $80^{\circ} \mathrm{C}$. The water bath was then slowly cooled to room temperature. The solution in the vassal was stored in a refrigerator, if necessary, before CE determination. Hybridized dsDNA was stable for more than one month.

\section{Results and Discussion}

\section{Separation condition}

First, FITC-labeled DNA is used as a probe to optimize the experimental conditions. It is desired to use the same buffer solution to the hybridization buffer in order to minimize the effect of diffusion of ionic species in $\mathrm{CE}$, since it results in peak broadening during sample separation. However, the sodium concentration of the hybridization buffer is too high, which substantially increases the electric conductivity of the solution. This increases the temperature of the solution by Joule heating and degrades the sample separation in CE. In fact, remarkable peak broadening was observed when the hybridization buffer was used as the separation buffer. One possible approach to overcome this problem is to use an additive with a low electric conductivity and a high ionic strength and to minimize the concentration of the phosphate buffer. Sodium dodecylsulfate was chosen as the additive in this study. The use of SDS changes the separation mode from $\mathrm{CE}$ to micellar electrokinetic chromatography (MEKC). The separation of oligonucleotides by MEKC has already been demonstrated by Cohen et al., and no interaction between SDS and oligonucleotides was observed in their work ${ }^{21}$, which might be attributed to an electric repulsion between the oligonucleotide and the dodecylsulfate anion. Similarly, SDS has been speculated not to interact with ds-DNA. Thus, SDS was added to the separation buffer throughout this work.

Figure 2A shows an electropherogram for ss-DNA labeled with FITC. Only a single peak is observed for ss-DNA for a migration time of $7.5 \mathrm{~min}$. Figure $2 \mathrm{~B}$ is an electropherogram for a mixture of probe : $\operatorname{target}=1: 1$. Although a strong peak is observed as in the case of Fig. 2A, the migration time is lengthened to $8.6 \mathrm{~min}$, and is apparently different from that in Fig. 2A. Thus, the peak observed in Fig. 2B can be assigned to ds-DNA formed by hybridization of target DNA with probe DNA. In Fig. 2C, two peaks appear, whose migration times are identical to those in Fig. 2A and 2B. Thus ds-DNA and excess ss-DNA are observed in this electropherogram. According to the theory reported by Mayer et al., long DNA fragments would sometimes have higher electrophoretic velocities than short DNA fragments depending on the chemical reagent end-labeled in free-solution CE, which is in contrast to gel electrophoresis. ${ }^{22}$ Though ds-DNA is twice as large as ssDNA, it has two times as many bases than ss-DNA. Hence, ds-DNA can have a higher electrophoretic velocity than ss-DNA by modification with end-labeled FITC. Therefore, the result of the experiment does not necessarily contradict the theoretical expectation. Thus, FITC plays an important role not only as a 

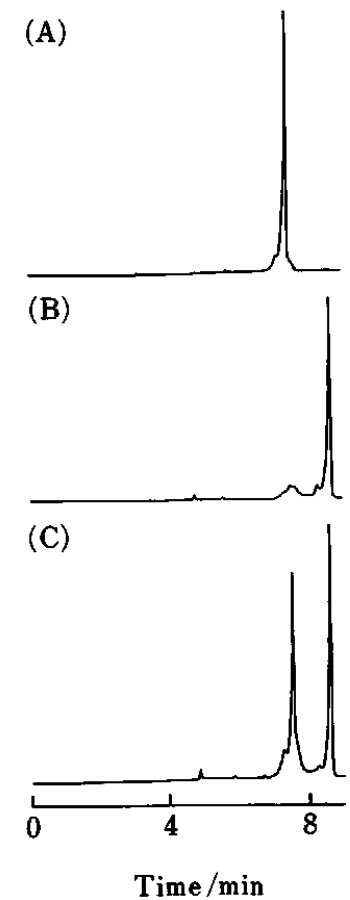

Fig. 2 Electropherograms for DNA labeled with FITC. Conditions: concentration $(\mu \mathrm{M}),(\mathrm{A})$ probe $=3.8$, target $=0$, (B) probe $=3.8$, target $=3.8$, (C) probe $=7.6$, target $=3.8$; injection time, $2 \mathrm{~s}$; buffer, $10 \mathrm{mM} \mathrm{NaH} \mathrm{PO}_{4}-5 \mathrm{mM}$ Tris containing $60 \mathrm{mM}$ SDS; light source, argon ion laser, $488 \mathrm{~nm}, 24 \mathrm{~mW}$. The applied voltage was adjusted to $20 \mathrm{kV}$ $(33 \mu \mathrm{A})$. The other conditions are described in the text.

fluorescence labeling reagent, but also as a modifier to change the electrophoretic mobility of DNA. A similar result was obtained without using SDS, which also implies that ss-DNA and ds-DNA are separated by CE, i.e. the difference between the ratios of the electric charges to its friction coefficients.

\section{Stability of ds-DNA}

As described above, ds-DNA can possibly be dissociated by the Joule heat generated during a migration process. The Joule heat can be controlled by adjusting the applied voltage (or current). Thus the effect of the voltage on the stability of ds-DNA was investigated in this study. Figure 3 shows electropherograms for a mixture of probe : target $=2: 1$ at various migration voltages. At the lowest voltage, the peak height of ds-DNA is similar to that of ss-DNA (Fig. 3A). Although the experiment was also performed below $20 \mathrm{kV}$, there was essentially no change in the peak intensities for ss-DNA and ds-DNA. However, at high voltages (Fig. 3B-D) the peak height of ds-DNA decreases and the peak shape is appreciably degraded.

There are two possible explanations for the dissociation of ds-DNA: one is the effect of a high electric field as reported by Chen et al: $;^{16}$ the other is the effect . of a temperature rise caused by Joule heating during migration. The former occurs due to a disruption of
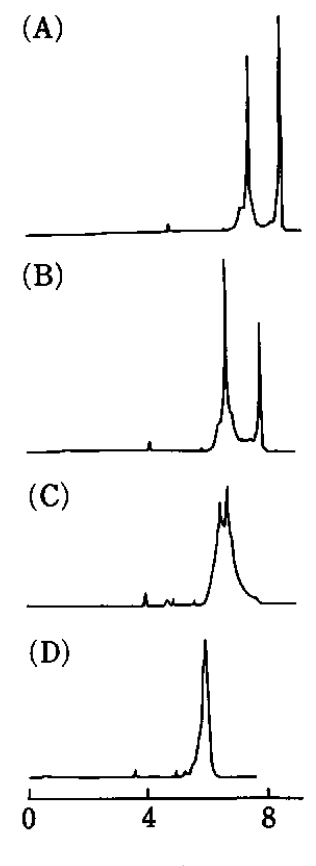

Time $/ \mathrm{min}$

Fig. 3 Effect of the applied voltage on the stability of doublestranded DNA. (A) $20 \mathrm{kV}, 33 \mu \mathrm{A}$, (B) $22 \mathrm{kV}, 38 \mu \mathrm{A}$, (C) $23 \mathrm{kV}, 40 \mu \mathrm{A}$,(D) $24 \mathrm{kV}, 44 \mu \mathrm{A}$. The same sample to that in Fig. 2B (probe : target=1:1) was used. The other experimental conditions were identical to those given in Fig. 2, except for the applied voltage.

imperfectly annealed ds-DNA. The later effect may be explained as follows. The melting temperature $\left(T_{\mathrm{m}}\right)$ of $19 \mathrm{mer}$ DNA was determined to be $64-66^{\circ} \mathrm{C}(100 \mathrm{mM}$ of sodium ion, phosphate buffer, $\mathrm{pH} 7$ ) by conventional spectrophotometry. The concentration of sodium ions in the carrier solution was $60 \mathrm{mM}$, and the $T_{\mathrm{m}}$ value was estimated to $<64^{\circ} \mathrm{C}$. Terabe $e t$ al. have reported that the temperature of the carrier solution in the capillary was increased to $59-77^{\circ} \mathrm{C}$ at a voltage of $308 \mathrm{~V} \mathrm{~cm}^{-1}$ $(61.4 \mu \mathrm{A}) .^{23}$ In Fig. 3B, since the applied voltage is 400 $\mathrm{V} \mathrm{cm}-1(38 \mu \mathrm{A})$ the temperature of the carrier solution would be increased to $>T_{\mathrm{m}}$, although it is difficult to accurately evaluate the exact value. In Figs. $3 \mathrm{C}$ and 3D, ds-DNA is completely dissociated. The broad peak can be understood by assuming that ds-DNA is dissociated on the way to the detector. Unfortunately, it is difficult to specify which effect is more dominant in our study, since the high voltage and the temperature of the solution in the capillary cannot be changed independently. However, the results shown in Fig. 3 indicate that control of the migration voltage and current is important to suppress the dissociation of ds-DNA.

\section{Semiconductor LIF}

In order to simplify the analytical instrument, a semiconductor laser was used as an exciting light source in this study. Figure 4 shows the absorption spectrum 


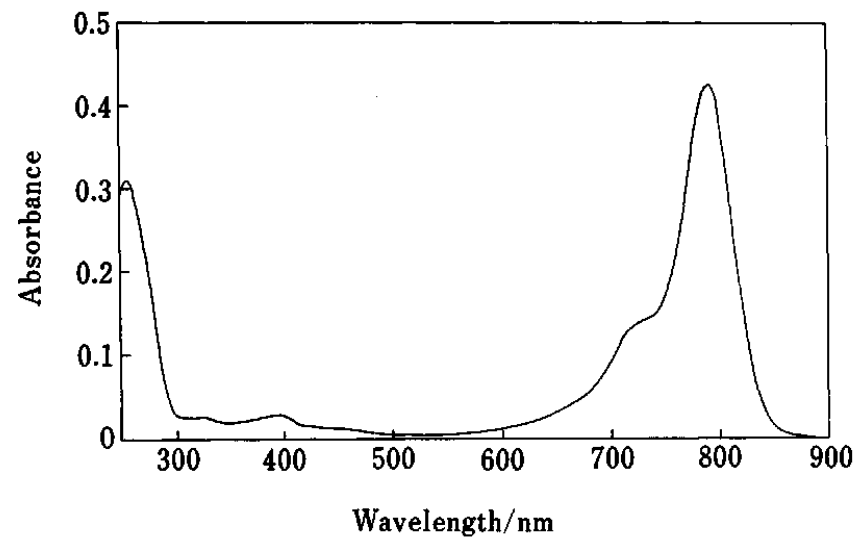

Fig. 4 Absorption spectrum for DNA labeled with cyanine derivative. Sample concentration, $1.8 \mu \mathrm{M}$; buffer, $0.1 \mathrm{M}$ sodium phosphate $(\mathrm{pH}, 7.0)$.

of cyanine-labeled DNA. An absorption band in the ultraviolet region originated from a nucleic acid moiety and an absorption band in the near-infrared region from a cyanine moiety; these absorption bands coincide well with those of native DNA and of the labeling reagent of the cyanine derivative. The molar absorptivity at 788 $\mathrm{nm}$ is $c a .245000 \mathrm{~cm}^{-1} \mathrm{~mol}^{-1}$. On the other hand, there were no difference in the $T_{\mathrm{m}}$ values given for non-labeled, FITC-labeled, and cyanine-labeled DNA. This implies that there is no striking interaction between cyanine and the nucleic acid moieties. Thus the separation of ssDNA and ds-DNA labeled with the cyanine derivative was performed under the same experimental conditions determined by using FITC.

Figure 5 shows electropherograms obtained by using semiconductor LIF. The migration time of ds-DNA is different from that of ss-DNA, and they are clearly separated, as shown in Fig. 3. However, the migration times in Fig. 5 are different from those in Fig. 3. This might be attributed to difference of the tagged dye since the experimental conditions are all the same. FITClabeled DNA provides a better resolution between ss- and ds-DNAs than does cyanine-labeled DNA. On the other hand, the detection limit evaluated by employing ss-DNA as a sample was $8 \times 10^{-9} \mathrm{M}$, which is 6-times as low as that of FITC labeled DNA $\left(5 \times 10^{-8} \mathrm{M}\right)$. The sensitivity in the detection of FITC-labeled DNA is somewhat worse than those given in a published paper. ${ }^{24}$ The major reason is attributed to the fact that no investigation was performed in this study to improve the sensitivity, e.g. reduction of scattered light and unwanted fluorescence from a capillary and a buffer solution. However, another possible reason is attributed to severe peak broadening in CE. The theoretical plate number obtained in the separation of FITC-labeled DNA was 47000 , which is considerably smaller than that obtained in standard CE. This fact was caused by the high salt concentration of the sample solution, which was required in hybridization of DNA.

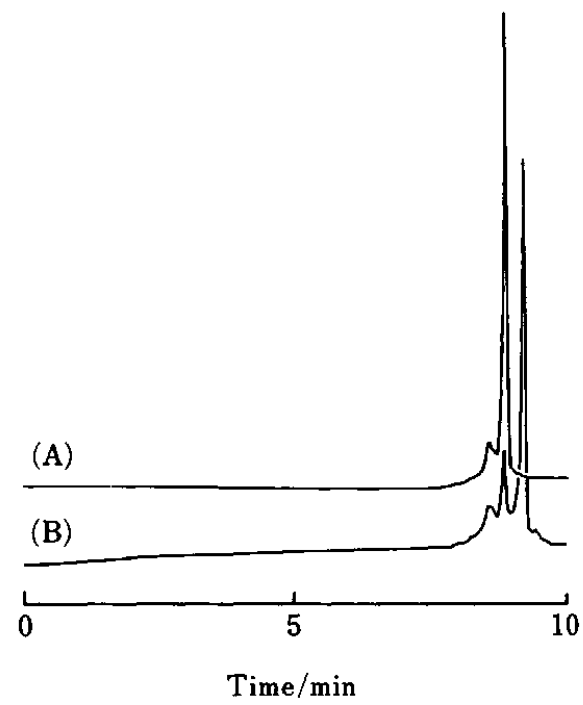

Fig. 5 Electropherogram for DNA labeled with cyanine derivative. Conditions: concentration $(\mu \mathrm{M}),(\mathrm{A})$ probe $=$ 3.3, target $=0$, (B) probe $=3.3$, target $=3.3$; light source, semiconductor laser, $780 \mathrm{~nm}, 10 \mathrm{~mW}$. The other conditions were identical to those in Fig. 2.

\section{References}

1. J. W. Jorgenson and K. D. Lukacs, Anal. Chem., 53, 1298 (1981).

2. J. W. Jorgenson and K. D. Lukacs, Science, [Washington, D.C.], 222, 266 (1983).

3. Y. F. Cheng and N. J. Dovichi, Science, [Washington, D.C.], 242, 562 (1988).

4. T. Imasaka and N. Ishibashi, Anal. Chem., 62, 363A (1990).

5. A. J. G. Mank, H. Lingeman and C. Gooijer, Tr. Anal. Chem., 11, 210 (1992).

6. T. Imasaka, Anal. Sci., 9, 329 (1993).

7. T. Imasaka, Spectrochim. Acta Rev., 15, 329 (1993).

8. T. Higashijima, T. Fuchigami, T. Imasaka and $\mathrm{N}$. Ishibashi, Anal. Chem., 64, 711 (1992).

9. T. Imasaka, K. Nishitani and N. Ishibashi, Analyst [London], 116, 1407 (1991).

10. T. Fuchigami, T. Imasaka and M. Shiga, Anal. Chim. Acta, 282, 209 (1993).

11. H. Swerdlow and R. Gesteland, Nucleic Acids Res., 18, 1415 (1989).

12. J. A. Luckey, H. Drossman, A. J. Kostichka, D. A. Mead, J. D'Cunha, T. B. Norris and L. M. Smith, Nucleic Acids Res., 18, 4417 (1990).

13. A. S. Cohen, D. R. Najarian and B. L. Karger, $J$. Chromatogr., 516, 49 (1990).

14. F. T. A. Chen, A. Tusak, S. Pentoney, K. J. Konrad, C. Lew, E. Koh and J. Sternberg, J. Chromatogr. A, 652, 355 (1993).

15. E. M. Southern, J. Mol. Biol., 98, 503 (1975).

16. J. W. Chen, A. S. Cohen and B. L. Karger, J. Chromatogr., 559, 295 (1991).

17. D. J. Rose, Anal. Chem., 65, 3545 (1993).

18. M. Vilenchik, A. Belenky and A. S. Cohen, J. Chromatogr. A, 663, 105 (1994). 
19. R. G. Brownlee, F. J. Sunzeri and M. P. Busch, $J$. Chromatogr., 533, 87 (1990).

20. C. Carlsson, M. Jonsson, B. Norden, M. T. Dulay, R. N. Zare, J. Noolamdi, P. E. Nielsen, L. Tsui and J. Zielenski, Nature [London], 380, 207 (1996).

21. A. S. Cohen, S. Terabe, J. A. Smith and B. L. Karger, Anal. Chem., 59, 1021 (1987).

22. P. Mayer, G. W. Slater and G. Drouin, Anal. Chem., 66, 1777 (1994).
23. S. Terabe, K. Otsuka and T. Ando, Anal. Chem., 57, 834 (1985).

24. H. Drossman, J. A. Luckey, A. J. Kostichka, J. D'Cunha and L. M. Smith, Anal. Chem., 62, 900 (1990).

(Received August 2, 1996) (Accepted September 2, 1996) 